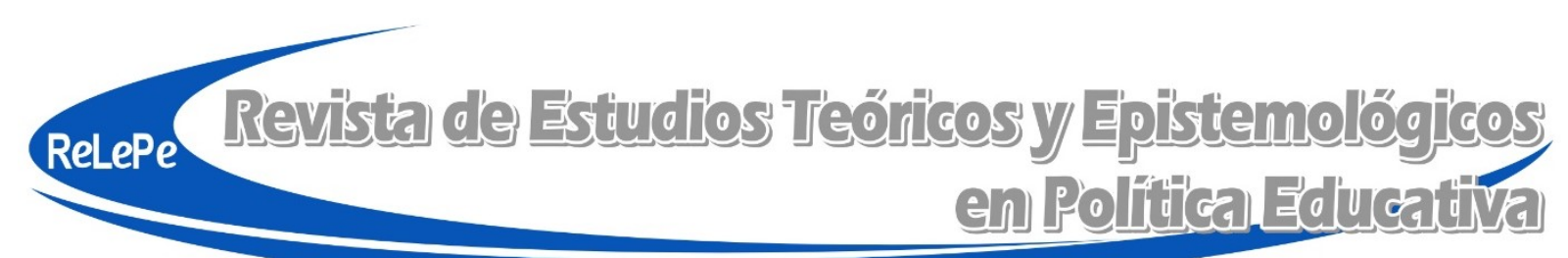

ISSN 2409-3696

do) https://doi.org/10.5212/retepe.v.6.18187.010

\title{
Fundamentos político-pedagógicos da BNCC: considerações sobre o Estado educador e a produção de hegemonia
}

\section{Political-pedagogical foundations of the $B N C C$ : considerations about the educational State and the production of hegemony}

\section{Fundamentos políticos y pedagógicos de la BNCC: consideraciones sobre el Estado educador y la producción de la hegemonía}

\author{
Paulo Fioravante Giareta ${ }^{*}$ \\ (iD) https://orcid.org/0000-0002-0649-4756
}

\begin{abstract}
Resumo: Este artigo objetiva fazer um exercício teórico de análise das características político-pedagógicas da Base Nacional Comum Curricular (BNCC), como expressão do Estado na qualidade de mediador de relações hegemônicas no contexto brasileiro. Metodologicamente, este trabalho estrutura-se a partir do materialismo histórico-dialético, fundamentado na concepção teórica de Antonio Gramsci, que compreende o Estado como organismo complexo e afeito técnica, ética e intelectualmente à racionalidade hegemônica. O trabalho indica que a BNCC, como ferramenta de intervenção política, portanto pedagógica do Estado, tanto incide sobre os processos de construção de consensos com marcada fidelidade à sociabilidade hegemônica, quanto busca disciplinar de forma direta a prática educativa, o que significa incidir sobre as próprias intencionalidades da comunidade educativa, consequentemente no controle e no disciplinamento das forças que indicam caminhos para a construção de outras experiências de sociabilidade que não a hegemônica.
\end{abstract}

Palavras-chave: Política educacional. Política curricular. Base Nacional Comum Curricular.

Abstract: This article aims to carry out a theoretical analysis of the political-pedagogical characteristics of the Common Core State Standards (in Brazil, Base Nacional Comum Curricular - BNCC), as an expression of the State as a mediator of hegemonic relations in the Brazilian context. Methodologically, this work is structured from the dialectical historical materialism, based on the theoretical conception of Antonio Gramsci, which understands the State as a complex organism and technically, ethically and intellectually attached to hegemonic rationality. The work indicates that the BNCC, as a tool of political intervention, therefore pedagogical of the State, both focuses on the processes of building consensus with marked fidelity to hegemonic sociability and seeks to directly discipline educational practice, which means to focus on the very intentions of the educational community, consequently in the control and disciplining of the forces that indicate paths for the construction of experiences of sociability other than the hegemonic one.

Keywords: Education policy. Curriculum policy. Common Core State Standards.

\footnotetext{
* Pós-Doutorando no Programa de Pós-Graduação em Educação da Universidade Estadual de Ponta Grossa (UEPG). Professor da Universidade Federal de Mato Grosso do Sul (UFMS), Campus de Três Lagoas (CPTL). E-mail: <pfgiareta27@yahoo.com.br>.
} 
Fundamentos político-pedagógicos da BNCC: considerações sobre o Estado educador e a produção...

Resumen: El objetivo de este artículo es realizar un ejercicio teórico de análisis de las características políticas y pedagógicas de la Base Nacional Común Curricular (BNCC), como expresión del Estado como mediador de las relaciones hegemónicas en el contexto brasileño. Metodológicamente, este trabajo se estructura a partir del materialismo histórico dialéctico, basado en la concepción teórica de Antonio Gramsci, que entiende el Estado como un organismo complejo y afectado técnica, ética e intelectualmente a la racionalidad hegemónica. El trabajo indica que la BNCC, como herramienta de intervención política, por lo tanto pedagógica del Estado, incide tanto en los procesos de construcción de consensos con una marcada fidelidad a la sociabilidad hegemónica, mientras busca disciplinar de forma directa a la práctica educativa, lo que significa incidir sobre las propias intenciones de la comunidad educativa, en consecuencia, en el control y disciplinamiento de las fuerzas que señalan los caminos para la construcción de otras experiencias de sociabilidad que no la hegemónica.

Palabras clave: Política educativa. Política curricular. Base Nacional Común Curricular.

\section{Introdução}

Neste texto, propõe-se a fazer um exercício teórico de análise das relações movimentadas pelo Estado brasileiro para a construção da Base Nacional Comum Curricular (BNCC). A proposição da BNCC é justificada nos marcos do ordenamento jurídico do Estado, tanto pela Carta Constitucional de 1988 (BRASIL, 1988) e pela Lei de Diretrizes e Bases da Educação Nacional (LDB) - Lei N$^{\circ}$ 9.394, de 20 de dezembro de 1996 (BRASIL, 1996), quanto pela aprovação e pela implementação de instrumentos de gestão estatal da política educacional, como o Plano Nacional de Educação (PNE) 2014-2024, por meio da Lei No 13.005, de 25 de junho de 2014 (BRASIL, 2014). É, assim, um conjunto de normativas legais que fundamenta amplo processo de debate sobre a regulação da oferta educacional a partir de bases curriculares comum.

Esse ordenamento jurídico-normativo, como instrumento de atuação do Estado, é assumido, aqui, como estrutura mediada pela concepção de sociabilidade hegemônica, portanto política e, consequentemente, pedagógica, conforme a conceituação sistematizada pelo intelectual Antonio Gramsci (1968a, 1968b). Posicionamento teórico-metodológico que demanda a análise do debate e da produção de políticas educacionais, tais como: a política curricular da BNCC, pelo Estado, como expressão da movimentação dos aparelhos de hegemonia na produção e na validação de intencionalidades político-pedagógicas concernentes à sociabilidade vigente.

Metodologicamente, o trabalho expressa-se como exercício analítico-crítico, com aporte no materialismo histórico-dialético, enquanto "[...] exercício situado no plano da realidade, no plano da história, sob a forma de trama de relações contraditórias, conflitantes, de leis de construção, do desenvolvimento e da transformação dos fatos" (FRIGOTTO, 1997, p. 75), bem como uma possibilidade teórica e um instrumento lógico de interpretação da realidade, sendo capaz de indicar um caminho epistemológico para o exercício da interpretação da proposta em análise (BENITE, 2009). Na definição de Saviani (2015, p. 79), é um exercício "[...] que vai das observações empíricas (o todo figurado na intuição) ao concreto (uma rica totalidade de determinações e de relações numerosas) pela mediação do abstrato (a análise, o conceito e as determinações mais simples)", como processo dialético de produção de conhecimento.

\section{Considerações teórico-metodológicas: aproximações sobre Estado e hegemonia}

A preocupação com o Estado na tradição ocidental remonta ao século IV antes da era cristã, com ampla referência à produção intelectual grega, quer pela busca do idealismo platônico afeto à própria organização da república como espaço para a vida virtuosa, quer pelo realismo político aristotélico. Essa discussão confere tradição às abstrações históricas do ideário de republicanismo democrático espelhado pela ideia da pólis grega, como representativo da 
participação popular na tomada de decisões sobre a organização da vida em sociedade (ARAÚJO; ALMEIDA, 2010). Esse mesmo princípio, posteriormente, foi vinculado ao pragmatismo jurídico - representativo - do Estado Romano.

O Estado, orientado pela busca da virtude, que parece tanto se assentar no idealismo do governo dos filósofos, como governança compartilhada entre homens livres e dialéticos (filósofos), quanto no Estado imperial republicano - governo representativo - dos romanos livres, na prática, não conseguiu extrapolar a representação de uma pólis grega e de um senado romano regulado e possível para não mais que cinco por cento de ambas as populações.

Embora a representação de Estado alimente-se, filosoficamente, no ideário greco-romano, a experiência teórica e prática de organização de Estado que marca a experiência social contemporânea é uma produção moderna, afeita às provocações do Príncipe de Maquiavel (1532) e sistematizada teoricamente sobre as formulações dos chamados filósofos contratualistas do século XVII e XVIII: Thomas Hobbes (1588-1651), John Locke (1632-1704) e Jean-Jacques Rousseau (1712-1778) (ARAÚJO; ALMEIDA, 2010) e pela abstração dialética e idealista de um Estado como encarnação da Razão Universal em Hegel (1770-1831), que parece guardar a expectativa de que o Estado seja depositário de uma certa evolução natural do espírito humano (MÉSZÁROS, 2006).

A elaboração filosófica dos contratualistas e da hermenêutica hegeliana naturaliza a percepção de que a vida, em sociedade, demanda a formalização de contratos e de ordenamentos sociais e jurídicos, que, em última análise, implicam a própria definição de modelos de Estado e de governança com maior potencial de salvaguarda dos direitos individuais e privados no âmbito da vida coletiva.

Os denominados liberais clássicos, como Adam Smith, ainda em 1776, com a obra $A$ Riqueza das Nações, buscam tecer consensos com essa concepção de Estado e governança dos contratualistas e hegelianos, no sentido de o naturalizar, ética, política e culturalmente, às relações econômicas, enquanto esforço e direito individual privado. Uma concepção de Estado que ganha consistência na moderna organização político-econômica liberal, portanto burguesa, do capital, naturalizando e conferindo aderência à chamada lógica da mercadoria à sociabilidade que emerge, desde a sistematização teórica e prática dos direitos subjetivos, da posse privada dos bens, da liberdade e do direito ao exercício do individualismo econômico.

A análise sobre as contradições do Estado moderno, universalizado, guardião de um suposto evolucionismo natural, logo liberal, burguês - capital - fundamenta a chamada concepção marxista de Estado (MÉSZÁROS, 2006). O marxismo, partindo do reconhecimento de que a estrutura econômica da sociedade como conjunto das relações de produção, responde como base real sobre a qual se levanta a superestrutura jurídica e política e à qual correspondem determinadas formas de consciência social, compreende que o modo de produção da vida material condiciona o processo da vida social. Reconhece, por conseguinte, que o Estado não passa de um lócus de negociação dos interesses dessa burguesia. Desse modo, “[...] o executivo do Estado moderno não é mais do que um comitê para administrar os negócios coletivos de toda a classe burguesa" (MARX; ENGELS, 1998, p. 7). Assim, o Estado é expresso no contexto do pensamento político do marxismo em termos negativos, como disciplinamento, ordenamento político-jurídico burguês que deve ser superado. Estado classista, que, embora se justifique como guarda dos interesses universais e coletivos, compreende como interesse coletivo o que é comum a uma classe particular.

A perspectiva da negação do Estado em Marx é mediada pela práxis revolucionária, na qual implica a proposta de sua superação como afirmação histórica da realidade concreta dos indivíduos sociais, reduzindo a forma teorizada burguesa da expressão do Estado capital. Filosoficamente,

Revista de Estudios Teóricos y Epistemológicos en Política Educativa, v. 6, e2118187, p. 1-17, 2021 Disponible en: <https://www.revistas2.uepg.br/index.php/retepe>. 
Fundamentos político-pedagógicos da BNCC: considerações sobre o Estado educador e a produção...

representa uma contestação da própria dialética idealista e abstrata - universal, evolutiva, natural de Hegel, em que a ideia de Estado está a serviço de uma determinada lógica. Dessarte, a concepção marxista de Estado precisa ser compreendida a partir de sua teoria política, que, na prática, é uma teoria que pressupõe a sua superação pela autogestão social. Desse modo, ela compreende que o Estado é uma estrutura abstrata e que concreto é o povo. Assim, quando a condição concreta do povo se firma como autogestão e organização civil, material e histórica, a determinação do Estado político, portanto burguês, tem de desaparecer.

Essa concepção é reafirmada por Engels (1984), ao indicar que o Estado, como o conhecemos, é uma produção da própria sociedade capitalista, enquanto espaço de gestão das contradições de classe inerente à origem da apropriação privada da propriedade. Ao analisar a organização social ateniense, Engels (1984) indica que a substituição da troca entre tribos pela troca entre indivíduos, consequentemente, ao se transformar produtos em mercadorias, demandou o surgimento do próprio cultivo do solo de forma individual, criando espaço para o surgimento do dinheiro como mercadoria universal, como nova força social.

\begin{abstract}
A riqueza passa a ser valorizada e respeitada como bem supremo e as antigas instituições das gens são pervertidas para justificar-se a aquisição de riquezas pelo roubo e pela violência. Faltava apenas uma coisa: uma instituição que não só assegurasse as novas riquezas individuais contra as tradições comunistas da constituição gentílica, que não só consagrasse a propriedade privada, antes tão pouco estimada, e fizesse desta consagração santificadora o objetivo mais elevado da comunidade humana, mas também imprimisse o selo geral do reconhecimento da sociedade às novas formas de aquisição da propriedade, que se desenvolviam umas sobre as outras - a acumulação, portanto, cada vez mais acelerada, das riquezas -, uma instituição que, em uma palavra, não só perpetuasse a nascente divisão da sociedade em classes, mas também o direito de a classe possuidora explorar a não-possuidora e o domínio da primeira sobre a segunda. E esta instituição nasceu. Inventou-se o Estado. (ENGELS, 1984, p. 120).
\end{abstract}

Assim, Engels (1984) colabora com o deslocamento da compressão hegeliana de Estado como justificação determinista, de fora para dentro, como uma espécie de realidade da ideia moral ou imagem da realidade da ideia moral, mas a reconhece como produto social, consequentemente de certo estágio de seu desenvolvimento. Nesse sentido, é a confissão de uma sociedade que "[...] se enredou em uma irremediável contradição com ela própria e está dividida por antagonismos irreconciliáveis que não consegue conjurar" (ENGELS, 1984, p. 191). Essa constatação posiciona o Estado como produto do desenvolvimento social na perspectiva de classe, logo profundamente antagônico.

Para que esses antagonismos, essas classes com interesses econômicos colidentes não se devorem e não consumam a sociedade numa luta estéril, faz-se necessário um poder colocado aparentemente por cima da sociedade, chamado a amortecer o choque e a mantê-lo dentro dos limites da "ordem". Este poder, nascido da sociedade, mas posto acima dela se distanciando cada vez mais, é o Estado. (ENGELS, 1984, p. 191).

Para Engels (1984), o Estado não pode ser representado como realidade real, moral, idealmente representativa de um naturalismo evolucionista da sociedade, conforme indica a filosofia hegeliana, mas como estrutura de gestão dos conflitos das classes e produto da própria organização classista da sociedade. É, dessa maneira, uma estrutura jurídica e coercitiva a serviço "[...] da classe mais poderosa, da classe economicamente dominante, classe que, por intermédio dele, se converte também em classe politicamente dominante e adquire novos meios para a repressão e exploração da classe oprimida" (ENGELS, 1984, p. 193), pois, na perspectiva revolucionária, uma estrutura pode ser superada enquanto movimento histórico de superação da sociedade de classe.

Revista de Estudios Teóricos y Epistemológicos en Política Educativa, v. 6, e2118187, p. 1-17, 2021 Disponible en: <https://www.revistas2.uepg.br/index.php/retepe>. 
Antonio Gramsci, intelectual marxista italiano, no início do século XX, formula importantes contribuições para essa compreensão. Reconhecendo a natureza histórica e dialética da realidade, mais do que afirmar o Estado como uma estrutura naturalizada e abstrata, ou mesmo mecanicamente determinada pela subordinação da superestrutura à estrutura, o autor compreendeo como hegemonia intelectual e moral de uma certa concepção de mundo. Em outras palavras, é a afirmação histórica de um certo bloco como capacidade de domínio e direção, quer pela coerção, quer pelo consentimento voluntário do grupo dominado.

Essa concepção ganha representação histórica, a qual é denominada de sociedade política e sociedade civil, conferindo liberdade dialética para a superestrutura na relação com a estrutura objetiva. Nas palavras de Gramsci (1968a, p. 14), implica reconhecer que o Estado enquanto política "[...] é ação permanente e dá origem a organizações permanentes, na medida em que, efetivamente, identifica-se com a economia", podendo, contudo, compreendê-las de forma distinta, ou melhor, embora a ação política estabeleça relações permanentes e orgânicas com a vida econômica - estrutura - figura, também, como força superadora, conferindo centralidade à superestrutura.

Com marcada fidelidade à concepção histórica e contraditória da realidade, Gramsci posiciona o Estado na dialética da produção e do exercício da hegemonia, como exercício éticopolítico, mas também econômico. É um exercício histórico marcado pelas relações de força, que, ao mesmo tempo em que demandam certos sacrifícios de ordem econômica-corporativa, esses sacrifícios não se relacionam com o essencial, que o próprio Gramsci (1968a, p. 33) denomina de formação de "certo equilíbrio de compromisso".

Essas relações de força, para Gramsci (1968a), demarcam a própria consolidação histórica do Estado, que, em um primeiro momento, parece responder por um certo determinismo da relação de agrupamentos sociais em torno das forças materiais de produção, avançando para relações que denomina de forças políticas, como representativo de certo grau de homogeneidade, autoconsciência e organização dos grupos sociais. Para Gramsci (1968a), essas forças políticas também são representadas por distintos movimentos que partem de certa solidariedade econômico-corporativa entre grupos específicos, passando pelos movimentos de construção de uma homogeneidade e solidariedade de interesse entre todos os grupos sociais econômicos, já posicionando o Estado como estrutura jurídico-política até chegar no momento da compreensão de que os próprios interesses corporativos extrapolem os interesses de grupos meramente econômicos, podendo e devendo torna-se o interesse de outros grupos subordinados.

É a fase mais abertamente política, que assinala a passagem nítida da estrutura para a
esfera das superestruturas complexas; é a fase em que as ideologias germinadas
anteriormente se transformam em "partido", entram em choque e lutam até que uma
delas, ou pelo menos uma combinação delas, tende a prevalecer, a se impor, a se irradiar
em toda área social, determinando, além da unicidade dos fins econômicos e políticos,
também a unidade intelectual e moral. Coloca todas as questões em torno das quais se
acende a luta não num plano corporativo, mas num plano "universal", criando, assim, a
hegemonia de um grupo social fundamental sobre uma série de grupos subordinados.
(GRAMSCI, 1968a, p. 50).

Assim, o Estado passa a ser compreendido como organismo próprio de um grupo e a serviço do expansionismo máximo desse grupo. O Estado é, então, “[...] todo o complexo de atividades práticas e teóricas com as quais a classe dirigente justifica e mantém não só o seu domínio, mas consegue obter o consentimento ativo dos governados" (GRAMSCI, 1968a, p. 87). Nessa concepção, confere-se centralidade ao conceito de hegemonia. Para Jesus (1989):

Em Gramsci, portanto, o conceito de hegemonia é apresentado em toda sua plenitude, isto é, como uma ação que atinge não apenas a estrutura econômica e a organização

Revista de Estudios Teóricos y Epistemológicos en Política Educativa, v. 6, e2118187, p. 1-17, 2021 Disponible en: < https://www.revistas2.uepg.br/index.php/retepe>. 
Fundamentos político-pedagógicos da BNCC: considerações sobre o Estado educador e a produção...

política da sociedade, mas também age sobre o modo de pensar, de conhecer e sobre as orientações ideológicas e culturais. É neste sentido que as relações hegemônicas são pedagógicas e, como a realização da tarefa pedagógica implica a compreensão das contradições para transformá-las em uma concepção do mundo unitária e coerente, as relações pedagógicas são igualmente hegemônicas. (JESUS, 1989, p. 42).

Isso implica reconhecer que o esforço político (jurídico, coercitivo) e civil (consenso, direção) demandam movimentos pedagógicos (culturais, intelectuais, morais) em nome da organização hegemônica. Assim, para Gramsci, qualquer projeto hegemônico será pedagógico, como qualquer projeto pedagógico será hegemônico, fundamentando a natureza políticopedagógica do Estado, enquanto organização técnica, ética e intelectual (hegemônica) de certa concepção de mundo que também denomina de bloco histórico hegemônico. Essa constatação demanda que haja revisita, a partir de uma leitura dialética e orgânica, aos conceitos de sociedade política ou Estado, “[...] que correspondem à função de 'hegemonia' que o grupo dominante exerce em toda a sociedade e àquela de 'domínio direto' ou de comando, que se expressam no Estado, no governo jurídico" e de sociedade civil, “[...] isto é, um conjunto de organismos chamados comumente de privados", também denominados de aparelhos privados de hegemonia (GRAMSCI, 1968b, p. 11).

É no contexto dessas relações dialéticas e com marcada funcionalidade político-pedagógica com a sociabilidade técnica, ética e intelectual vigente que se posiciona, aqui, a escola, como aparelho privado de hegemonia e, nela, as políticas educacionais, no presente trabalho, representadas pelas reformas curriculares em curso no Brasil, especialmente na denominada nova BNCC. Contudo, antes de posicionar os princípios educativos (GRAMSCI, 1968b), portanto os fundamentos político-pedagógicos da afirmação e manutenção histórica de um certo bloco hegemônico, convém compreender qual é essa concepção de mundo, ou melhor, para qual hegemonia intelectual e moral o Estado devota suas intencionalidades e forças políticopedagógicas.

\section{A afirmação histórica de um bloco hegemônico: o industrialismo americanizado}

A busca pela identificação de um bloco histórico hegemônico, para e no qual o Estado se expressa educador, encontra respaldo no próprio exercício intelectual gramsciano. Gramsci (1968a), ao analisar o processo de desenvolvimento industrial americano, no início do século XX, em um texto denominado Americanismo e Fordismo, reconhece características de um movimento técnico e econômico-corporativo com potencial de afetação ética-intelectual-política do ordenamento das relações sociais - um movimento capaz de extrapolar o disciplinamento fabril e passar a ser assumido como disciplinamento também social e cultural.

Para Gramsci (1968a, p. 382), o americanismo e o fordismo respondem por racionalização econômica pragmática, sem grandes obstáculos no contexto social e histórico, o que potencializa a hegemonia como produto da fábrica sem marcada resistência política e ideológica. "A hegemonia vem da fábrica e, para ser exercida, só necessita de uma quantidade mínima de intermediários profissionais da política e da ideologia". Essa racionalização produtiva, para tornar-se viável, exige um novo tipo de trabalho, por conseguinte um novo tipo de homem, adaptado psicofisicamente à nova estrutura, porque a vida nessa indústria exige um processo de adaptação "[...] para determinadas condições de trabalho, de nutrição, de habitação, de costumes, etc., que não é inato, 'natural', mas requer uma assimilação" (GRAMSCI, 1968a, p. 39). Para tanto, exige, também, uma adaptação psicossocial e cultural: "[...] a americanização exige um determinado ambiente, uma determinada estrutura social (ou a vontade decidida de criá-la) e um determinado tipo de Estado" (GRAMSCI, 1968a, p. 388).

Revista de Estudios Teóricos y Epistemológicos en Política Educativa, v. 6, e2118187, p. 1-17, 2021 Disponible en: <https://www.revistas2.uepg.br/index.php/retepe>. 
Essa nova estrutura produtiva que extrapola o espectro fabril e força a adaptação social movimenta novos arranjos supraestruturais e o redesenho político (jurídico-legislativo) e civil (moral e intelectual), enquanto coerção ou consenso, com ampla instrumentalização dos aparelhos privados de hegemonia. Por sua vez, essa caracterização possibilita reconhecer, a partir de Gramsci (1968a), a afirmação histórica do industrialismo americano fordista como novo bloco hegemônico.

O Sociólogo do trabalho, Ricardo Antunes (2009), destaca que a racionalização técnica e científica da produção induzida pelo fordismo-taylorismo no contexto da sociabilidade capitalista, radicaliza a submissão do trabalho ao capital, movimento reflexo, também, na submissão de toda a estrutura social, inclusive do Estado, que, segundo o próprio Gramsci (1968a), melhor expressase como Estado liberal, como apego à livre iniciativa e ao individualismo econômico. Esse novo sistema de metabolismo social urbano-industrial (ANTUNES, 2009), representativo de um novo bloco histórico hegemônico (GRAMSCI, 1968a), postula não apenas a reordenação das bases produtivas, mas alcança a reprodução de nova sociabilidade capital, portanto pressupõe a própria intervenção pedagógica (técnica, moral e intelectual) do Estado. Dito de outra forma, a maquinaria industrial, aportada na racionalização científica e na divisão hierárquica do trabalho, tanto aponta para a reestruturação das bases produtivas e de acumulação do capital, quanto responde pelo ideário técnico e ético de reprodução desse modelo de produção e acumulação, impactando sobre o próprio modo de vida em sociedade (ANTUNES, 2009).

Mesmo as marcadas crises das décadas de 1970 e 1980, representadas por fatores como perda de capacidade lucrativa, esgotamento da produção e maior concentração de riqueza (ANTUNES, 2009), não são capazes de induzir processos de interrupção ou superação desse modelo de sociabilidade, mas fomentam processos de reestruturação e de reorganização da mediação hegemônica do capital sobre a produção e os processos de acumulação, conforme indicado pelo próprio Gramcsi (1968a), ao compreender as mudanças como manifestação mais recente e agressiva das fases de reorganização da produção capitalista já estruturada no contexto do nascimento do industrialismo. Nas palavras de Neves e Sant'Anna (2005):

\footnotetext{
O novo bloco histórico que se foi constituindo no início do século XX mantém até os dias atuais suas características essenciais. No plano econômico, a reprodução ampliada do capital - sob a direção do grande capital, a partir do emprego diretamente produtivo da ciência e da técnica -, a expropriação crescente do trabalho pelo capital e a extração da mais-valia, por intermédio da intensidade do trabalho e do aumento da produtividade da força de trabalho. No plano político, um Estado que intervém nos rumos da produção e nas relações político-sociais com vistas a legitimação dos padrões de relações sociais vigentes. (NEVES; SANT'ANNA, 2005, p. 20).
}

Nesse sentido, a reestruturação, na linguagem de Gramsci (1968a), estágio superior da forma de reprodução hegemônica do bloco histórico dominante, figura-se conservadora e, como tal, aprofunda a racionalidade científica já estabelecida, buscando adequações a partir de plataformas ainda mais tecnológicas e centradas em controles gerenciais mais rígidos, resultando na radicalização dos processos de controle e no enxugamento do número de trabalhadores, substituídos pelo aumento da maquinaria. Esse tipo de processo, segundo Neves e Sant'Anna (2005), é instrumentalizado pelo Estado burguês como resposta à crise estrutural da acumulação do capital e para a reestruturação das relações de poder em nível local e internacional.

É nesse contexto que se compreende a aproximação do modelo industrial americano à proposta japonesa do Toyotismo como modelo centrado em bases mais flexíveis de produção e em indicadores de qualidade por etapas produtivas - eliminação de desperdício -, atendendo com maior precisão às demandas de mercado sem paralização do capital (ALVES, 2011). Na prática, resultou em uma proposta de reestruturação assentada em suportes formativos que intensificaram 
Fundamentos político-pedagógicos da BNCC: considerações sobre o Estado educador e a produção...

a supervisão do não desperdício de matéria prima, tempo e força laborais, perante uma expressiva intenção monopolista de fiscalização e de controle (ANTUNES, 2009).

Assim, o processo de reorganização das relações de produção, acumulação e poder figurase condicionado a uma ampla agenda de flexibilização das relações de trabalho, terceirização das plantas produtivas, desburocratização administrativa e organização produtiva, que, no limite, assume como estrutural o próprio sistema da desocupação laboral - desemprego estrutural; crise estrutural. Processo que se viabiliza pela busca da flexibilização radical e pela precarização total, conduzindo movimentos de reformismo constante de desregulamentação das leis trabalhistas, das políticas de seguridade social e contratual, da terceirização irrestrita e do controle fiscal do fundo público pelos setores financeiros em detrimento do trabalho e dos trabalhadores (ANTUNES, 2018).

Esse processo de flexibilização radical recebe contornos oficiais, especialmente para os países periféricos do sistema capitalista, por isso fiadores dessa concepção hegemônica, no denominado Consenso de Washington, em 1989, que pactua uma ampla agenda de reordenamento legal desses Estados a partir da propalada disciplina fiscal, controle de gastos públicos, adoção de marcos legais simpáticos à liberação do setor financeiro e comercial, indução de reformas tributárias e das políticas privatizantes (SILVA, 2002). Logo, essa agenda reformista passa a ser denominada de neoliberal. Em vista disso, o chamado Estado neoliberal figura-se e expressa-se como movimento inerente aos esforços de reorganização das relações de produção e de acumulação representativa da agenda do bloco hegemônico, caracterizado pelo americanismo industrial do século XX. Contudo, uma sociabilidade hegemônica que passa a operar sobre a profunda contradição de produzir consensos sobre uma agenda que assume a exclusão laboral, consequentemente a exclusão social como estrutural, ou melhor, como processo inerente à caracterização do Estado neoliberal.

O esforço em produzir consensos sob tais condições remete, novamente, à concepção de Estado em Gramsci (1968a), como estrutura complexa que opera sob a produção e o exercício da hegemonia, ora como herdeiro do disciplinamento econômico vigente, ora no exercício éticopolítico-intelectual adaptativo dos sujeitos ao referido ordenamento. Todavia, assumindo que o modelo hegemônico incorpora a exclusão estrutural como inerente ao seu ordenamento atual, fazse oportuno reconhecer que o Estado neoliberal se apresenta como alternativa de gestão da referida crise estrutural e não como estratégia para sua superação. Para tal, precisa operar sobre a lógica de ampliação de sua atuação sobre a práxis social, conceituação mais bem entendida, em Gramsci (1968a), como "estado ampliado".

Destaca-se que, agora, os aparelhos privados de produção de hegemonia, especialmente a escola, não apenas operam, conforme já anunciado no texto, no contexto das relações dialéticas características da afirmação histórica do bloco hegemônico e em sua marcada funcionalidade político-pedagógica, portanto técnica, ética e intelectual, mas também os precisam fazer enquanto gestão explícita da contradição da exclusão estrutural - laboral e social -, naturalizada como efeito inerente à reorganização das relações de produção e de acumulação em estágio superior dessa sociabilidade hegemônica.

\section{Fundamentos político-pedagógicos da BNCC como expressão do Estado educador}

Convém destacar de imediato, a partir da fundamentação indicada, que a atuação do Estado pela política educacional, expressa na política curricular da BNCC, não representa um deslocamento dos fundamentos político-pedagógicos hegemônicos, distante, por conseguinte, do alinhamento já proposto pelo reformismo curricular em curso, no sistema educacional brasileiro,

Revista de Estudios Teóricos y Epistemológicos en Política Educativa, v. 6, e2118187, p. 1-17, 2021 Disponible en: <https://www.revistas2.uepg.br/index.php/retepe>. 
desde a década de 1990. Essa constatação demanda, consequentemente, o reconhecimento da natureza e da função educativa do Estado, enquanto ordenamento ético e intelectual na perspectiva da reconfiguração e/ou da reprodução da racionalidade hegemônica, que emerge do capitalismo urbano-industrial no século XX, expresso na ideia de Estado liberal, que agora atende pelo neologismo de Estado neoliberal.

A caracterização estatal hegemônica que radicaliza seu apego às teses liberais neoliberalismo - é oficiada, conforme já indicado no texto, no contexto brasileiro, pela pactualidade em torno do denominado Consenso de Washington, passando a movimentar suas forças políticas e, assim, também pedagógicas, no sentido da acomodação ideológica dessa proposta de sociabilidade. A intencionalidade político-pedagógica encontra na escola - aparelho privado de hegemonia - profunda aderência nas políticas curriculares.

Concomitante e de forma consequente ao referido pacto articulado em 1989, é possível identificar no contexto brasileiro grandes esforços na promoção do que Melo e Faleiros (2005) denominam de reforma da aparelhagem estatal, como nova estratégia para a legitimação social de reposicionamento do arranjo hegemônico. Esse reformismo estatal expressa-se pedagógico para o ideário vigente, por isso com incidência direta sobre o sistema educacional.

O Estado educador neoliberal, na reforma da aparelhagem escolar - reformismo educacional -, parece conferir centralidade à política curricular, que, já no pacto federativo brasileiro de 1988, anuncia a necessidade de gestão de um currículo mínimo ou comum, expresso inicialmente, ainda na década de 1990, pela proposta de parametrização curricular oficializada na política dos Parâmetros Curriculares Nacionais (PCN), subsidiada, na sequência, pela política das Diretrizes Curriculares Nacionais (DCN), que, a partir de 2017, recebe forte incidência reguladora pela política da BNCC.

Assim, a política curricular como ferramenta do Estado neoliberal e de seu compromisso político, portanto pedagógico, com a agenda de reestruturação da sociabilidade capital em curso no contexto brasileiro, expressa-se a partir de dois movimentos principais: a) pelo esforço de garantir a ampliação hegemônica do Estado neoliberal, viabilizando a inferência direta do mercado sobre a produção das políticas educacionais; b) pela intervenção direta do Estado neoliberal sobre as intencionalidades político-pedagógicas da ação educativa, expressa tanto pelo apego às pedagogias das competências e o alinhamento das matrizes de oferta com as matrizes avaliativas, quanto pela indução de amplo processo de incidência sobre as políticas de formação dos profissionais da educação. A análise detalhada desses movimentos não figura possível neste trabalho, mas sim sua aproximação indicativa suficiente para demonstrar as referidas caracterizações.

\section{a) A hegemonia de mercado sobre a produção da política curricular}

A consolidação do bloco hegemônico, aqui representado pelo denominado industrialismo americanizado urbano-industrial com potencial de mundialização de uma nova ordem capitalista, ganha impulso no contexto das transformações geopolíticas decorrentes dos acordos que marcaram o fim da Segunda Guerra Mundial em 1945. Essa afirmação histórica, contudo, não se dá de forma espontânea, mas como indução de um processo racionalizado de dependência e associação de países ao mundo capitalista " [...] cuidadosamente pensada a partir dos conceitos de planejamento de época, centralizando decisões e consolidando a hegemonia dos Estados Unidos no mundo sob o conceito de interdependência" (MELO, 2005, p. 70).

Entretanto, a manutenção de uma hegemonia ativa, que na leitura gramsciana está implicada com o domínio e direção de forma indissociável, exige tanto a conformação de um modelo de 
Fundamentos político-pedagógicos da BNCC: considerações sobre o Estado educador e a produção...

Estado possível e funcional ao novo ordenamento capital, bem como de sua atuação educativa (político-pedagógica) na perspectiva do consenso, direcionando os desejos e as ações do conjunto da sociedade, especialmente daqueles que vivem do trabalho, para o projeto hegemônico de sociabilidade em curso.

O aparelhamento estatal de produção e de reprodução social desse ordenamento hegemônico e a própria gestão de suas contradições expressa-se por agenciamentos multilaterais capitaneados pela denominada Organização da Nações Unidas (ONU), como agência de planejamento e indução da sociabilidade hegemônica. Amplamente propagada como gestora de consensos supraestatais do mundo capitalista, ela se estrutura como organismo internacional de agenciamento de relações sociais, culturais, laborais econômicas e educacionais, que, na tradição gramsciana, é mais bem definido como organismos culturais, políticos e econômicos. Esses organismos estruturam-se a partir de agências como: Organização Internacional do Trabalho (OIT), Organização para a Cooperação e Desenvolvimento Econômico (OCDE), Organização Mundial da Saúde (OMS), Fundo Monetário Internacional (FMI), Banco Internacional para Reconstrução e Desenvolvimento (BIRD), do Grupo Banco Mundial (BM), e Banco Interamericano de Desenvolvimento (BID), Organização das Nações Unidas para a Educação (Unesco). Por conseguinte, essas agências têm forte poder de indução de políticas e produção de consensos a partir de pautas centralizadas como afirmação do ideário hegemônico.

Esse agenciamento figura-se ainda mais pertinente face ao deslocamento das crises de conjuntura constitutiva da hegemonia em curso até a década 1970 para a denominada crise estrutural da sociabilidade capitalista, que passa a assumir, a partir da década de 1980, conforme já indicado no texto, a desocupação laboral, portanto também social, como estrutural ao novo ordenamento social. Assim, os organismos internacionais, no conjunto da aparelhagem privada de produção de hegemonia, ganham centralidade como agenciadores de consenso e de reformas capazes, não de superar, mas de gerir o contexto de exclusão estrutural e construir cenários de adaptabilidade. De forma consequente, o poder de incidência dos organismos internacionais reserva especial atenção para a relação trabalho e educação, movendo, especialmente, os estados periféricos do capitalismo como signatários de acordos e consensos internacionais que regulam sua atuação política, nela, a política educacional.

É nesse contexto que o Brasil entra na década de 1990 buscando conciliar, de um lado, consensos fiscais delimitados por agencias financeiras como FMI e pactuados no denominado Consenso de Washington, amplamente reconhecido como marco oficial da agenda neoliberal e, de outro, acordos e resoluções de conferências internacionais prevendo ações como educação para todos, educação inclusiva, educação alinhada aos marcos tecnológicos e à educação para a adaptação produtiva como desafio para o século XXI. Essas orientações são incorporadas, no contexto brasileiro, a partir de uma ampla agenda de reformas, desde a reforma do próprio Estado até seu sistema educacional, tendo como marco regulador a lógica de mercado - hegemonia de mercado. Razão pela qual o ideário de Estado neoliberal brasileiro passa a ser profundamente marcado pela sua ampliação, especialmente nas políticas educacionais, via aparelhos privados da hegemonia de mercado, representadas por fundações e organizações derivadas de grandes grupos empresariais e financeiros, comumente reconhecidos como terceira via (GIDDENS, 2001), ou organizações sociais (MARTINS, 2005).

É nesse todo que as orientações para o reformismo educacional no Brasil conferem centralidade às reformas curriculares enquanto orientação articulada às incidências dos organismos multilaterais, que, na linguagem gramsciana, se pode denominar de aparelhos privados de hegemonia do capital, os quais bancam a subordinação legal, política e econômica dos Estados nacionais às diretrizes neoliberais decorrentes do Consenso de Washington, visto que, no campo

Revista de Estudios Teóricos y Epistemológicos en Política Educativa, v. 6, e2118187, p. 1-17, 2021 Disponible en: <https://www.revistas2.uepg.br/index.php/retepe>. 
da relação trabalho e educação, estão expressos nas orientações e incidências políticas da Unesco, FMI, BIRD e BID, OIT, OCDE, entre outras. Assim, esse aparelhamento mercadológico incide sobre as políticas curriculares no Brasil desde a década de 1990, inicialmente com a política dos PCN, passando pela década de 2000 com a política das DCN, até a oficialização, em 2017, da política da BNCC.

No âmbito da reforma curricular expressa na BNCC, essa agenda de mercado é capitaneada pelo autodeclarado Movimento pela Base que se apresenta como grupo não governamental e apartidário de pessoas, organizações e entidades que lutam pela construção e pela implementação da BNCC. Na prática, o grupo é representativo da atuação de atores privados vinculados a empresas e instituições financeiras, tais como: Itaú, Bradesco, Santander, Gerdau, Natura, Fundação Lemann, Fundação Roberto Marinho, Fundação Victor Civita e Todos pela Educação, entre outros. Assim, são vistos enquanto interlocutores locais do ideário educativo dos já indicados organismos multilaterais.

Vale destacar a pesquisa de Bernardi, Uczak e Rossi (2018, p. 40), a qual indica que a relação do movimento empresarial na política educacional brasileira, com especial incidência sobre a BNCC, ao demonstrar que o Movimento pela Base foi criado antes mesmo da Portaria N$^{\circ} 592$, de 17 de junho de 2015, que institui a comissão de especialistas para a elaboração da proposta da BNCC (BRASIL, 2015). A referida pesquisa demonstra, ainda, que o autodeclarado apartidário e não governamental "Movimento pela Base" é composto pelos mesmos representantes do movimento empresarial "Todos pela Educação", representados pelas Secretarias Municipais (União Nacional dos Dirigentes Municipais de Educação - Undime) e Estaduais (Conselho Nacional de Secretários de Educação - Consed) de Educação, bem como por funcionários públicos vinculados ao Ministério da Educação (MEC) e representantes do Instituto Nacional de Estudos e Pesquisas Educacionais Anísio Teixeira (Inep), demonstrando relação e incidência direta dos grupos empresarias nas políticas educacionais, especialmente na BNCC.

Contudo, a expressão e a atuação política, portanto pedagógica de um Estado afeito à sociabilidade hegemônica, não restringe a sua incidência ao processo de construção de consensos pela movimentação de reformas alinhadas à racionalidade vigente. No entanto, é possível indicar que, pela reforma curricular da BNCC, busca-se incidir de forma direta até mesmo na prática educativa, na didática, no planejamento e na atuação dos professores. Incide, desse modo, sobre as próprias intencionalidades da comunidade educativa, consequentemente no controle das forças que possam indicar para a construção de outras experiências técnicas, éticas e intelectuais de sociabilidade que não a hegemônica.

\section{b) A incidência sobre a prática educativa como intencionalidade político- pedagógica do Estado neoliberal}

A incidência político-pedagógica da sociabilidade hegemônica pela atuação do Estado como fiador da racionalidade não está indicado, aqui, em termos hipotéticos ou especulativos, mas encontra respaldo no seu próprio movimento político e jurídico. A Resolução $\mathrm{N}^{o} 2$, de 22 de dezembro de 2017 (BRASIL, 2017), do Conselho Nacional de Educação (CNE), materializa essa carga de intencionalidades ao conferir centralidade às matrizes de competência e habilidades na organização curricular sob o anúncio de ser uma revolução epistemológica, promovida pela política curricular e uma resposta modernizante para as demandas dos desafios impostos pelo modelo hegemônico da relação educação e trabalho para o século XXI. Após a explicitação dessa centralidade pelo Art. $2^{\circ}$ da Resolução, o Art. $3^{\circ}$ define, inclusive, seu alcance: "No âmbito da BNCC, competência é definida como a mobilização de conhecimentos (conceitos e procedimentos), habilidades (práticas cognitivas e socioemocionais), atitudes e valores, para 
Fundamentos político-pedagógicos da BNCC: considerações sobre o Estado educador e a produção...

resolver demandas complexas da vida cotidiana, do pleno exercício da cidadania e do mundo do trabalho" (BRASIL. 2017, p. 4).

Orientação jurídico-normativa que, no parágrafo $1^{\circ}$ do Art. $5^{\circ}$, da Resolução No 2/2017, é apresentada como fundamento para a "[...] concepção, formulação, implementação, avaliação e revisão dos currículos, e consequentemente das propostas pedagógicas das instituições escolares" (BRASIL. 2017, p. 5), com impacto direto sobre a articulação e a coordenação de políticas e práticas educacionais, com especial atenção para aquelas voltadas "[...] à formação de professores, à avaliação da aprendizagem, à definição de recursos didáticos”(BRASIL. 2017, p. 5). Desse modo, a intencionalidade político-pedagógica retomada nas disposições finais e transitórias da Resolução devota quase a integralidade do item para reafirmar o compromisso da BNCC com a afetação direta ao espaço da prática educativa pela promoção de ampla reformulação da política formativa (formação de professores), alinhamento das matrizes avaliativas com a BNCC (sistema de avaliação) e da política de produção de livros didáticos (material didático).

Não obstante, os esforços de teóricos da educação em indicar uma fundamentação filosófica para a pedagogia das competências, como: o condutivismo, o funcionalismo, $\mathrm{O}$ construtivismo (RAMOS, 2002), a abordagem biologista e/ou inatista (SILVA, 2018), a tradição teórica que fundamenta o presente trabalho identifica-a como uma adequação pragmática da relação educação e trabalho no contexto da reconfiguração das bases de produção e acumulação do modelo hegemônico, especialmente no contexto da crise estrutural - exclusão laboral e social , com forte expressão sobre as estruturas educacionais, que, agora, tanto tem de responder pela progressiva flexibilização da produção e reestruturação das ocupações, quanto pela gestão das próprias consequências da desocupação laboral como inerentes a esses novos arranjos produtivos (RAMOS, 2002).

Nesse contexto, a aproximação da educação ao ideário de uma prática educacional funcional ao reordenamento produtivo, pressupondo o deslocamento da centralidade conferida ao conteúdo - cultura sistematizada - para comportamentos e atitudes previamente definidas competências e habilidades pré-definidas -, não é algo novo e nem uma exclusividade da BNCC, embora, com a política curricular da BNCC, a matriz de competência e habilidade receba o status de marco paradigmático capaz de induzir uma transformação epistemológica na educação brasileira.

Pesquisas, independentemente da abordagem teórica, indicam concordância, na linguagem de Silva (2018), de que a centralidade conferida pela BNCC à pedagogia das competências e habilidades representa o resgate de um empoeirado discurso, que figurou na educação brasileira no contexto das reformas curriculares conduzidas ainda na década de 1990, especialmente, pela política dos PCN. Para Silva (2018, p. 9), ainda que falando especificamente da BNCC do Ensino Médio, "[...] o documento recupera a proposição dos Parâmetros e Diretrizes Curriculares Nacionais da década de 1990, evidenciando a retomada de um discurso interrompido e amplamente criticado".

A propagada originalidade, inclusive epistemológica, confunde-se com os ordenamentos funcionais e pragmáticos exigidos pelo mercado de trabalho, no contexto da reorganização objetiva de suas bases produtivas e de sua legitimação ideológica, conduzida pelo Estado neoliberal para as políticas educacionais, centralmente pelas políticas curriculares, demandando reconhecer a política da BNCC como intervenção prescritiva e de controle, que, na linguagem gramsciana, representa a mediação da própria práxis social possível nas ações educativas em curso.

O ideário de controle, por sua vez, também não é novo e nem é alcançado por um ordenamento epistemológico, mas se retroalimenta na progressiva implementação de políticas

Revista de Estudios Teóricos y Epistemológicos en Política Educativa, v. 6, e2118187, p. 1-17, 2021 Disponible en: < https://www.revistas2.uepg.br/index.php/retepe>. 
avaliativas externas à prática escolar, avaliações de larga escala e padronizadas. Para Freitas (2014), esse ideário de controle começa a ganhar forma oficial na década de 1990, como primeiro movimento mais objetivo e organizado do Estado neoliberal no campo da educação e se alimenta ora pela precipitação racional de um amplo processo de controle da reflexão sobre a organização pedagógica da sala de aula, ora pelo seu deslocamento deliberado pela intervenção estatal como agente avaliativo desde fora.

Para Freitas (2014, p. 1090), a proposição de uma política curricular que se expressa como base comum nacional, assentada sobre objetivos de aprendizagem, reduz o direito à formação ampla e contextualizada, o enclausurando no chamado direito de aprender o básico, já " [...] expresso nas matrizes de referência dos exames nacionais, assumido ali como o domínio que é considerado 'adequado' para uma dada série escolar nas disciplinas avaliadas - não por acaso as que estão mais diretamente ligadas às necessidades dos processos produtivos". Em virtude disso, o processo produtivo está localizado nos limites da mediação hegemônica do capital.

Destaca-se que a definição do que é básico tem por referência a matriz avaliativa e não o currículo prescrito no projeto político-pedagógico da comunidade escolar, ou mesmo da própria BNCC. Assim, distancia-se do reconhecimento das motivações das reformas curriculares pela adequação da educação às propostas pedagógicas progressistas e/ou de arranjos epistemológicos outros - não normativos -, mas, contrariamente, a aproxima da lógica do controle da oferta e da promoção cultural pelas matrizes avaliativas externas à organização pedagógica e didática da escola.

\begin{abstract}
$\mathrm{Na}$ luta pelo controle do processo pedagógico das escolas, o Estado é cada vez mais disputado por forças sociais liberal-conservadoras que procuram assumir, por meio de avaliações externas, o controle e o fortalecimento dos processos de avaliação internos da escola (formais e informais) e a partir destes subordinar as categorias do processo pedagógico a seus interesses, vale dizer, preservar e aumentar o controle sobre os objetivos, o conteúdo e até sobre os métodos da escola. A organização do trabalho pedagógico da sala de aula e da escola ficou cada vez mais padronizada, esvaziando a ação dos profissionais da educação sobre as categorias do processo pedagógico, de forma a cercear um possível avanço progressista no interior da escola e atrelar esta instituição às necessidades da reestruturação produtiva e do crescimento empresarial. (FREITAS, 2014, p. 1092).
\end{abstract}

Contudo, esse ideário de controle não se dá fora de um contexto de disputa; assim sendo, ele precisa movimentar-se e afirmar-se a partir de um contexto histórico específico, marcado por profundas contradições e conduzidos por sujeitos afetados ética e intelectualmente pela práxis social. Assim, o Estado neoliberal tende a identificar esses sujeitos, na estrutura educacional escolarizada, naqueles responsáveis pela mediação docente - professores -, conferindo centralidade às reformas curriculares com potencial de disciplinamento político-pedagógico e técnico-ideológico dos docentes. É nesse contexto de disputa, orientado pela lógica de controle, que a política de formação de professores ocupa papel central, já que são os professores, no dia a dia da escola, que executam as intencionalidades político-pedagógicas para que o sistema continue funcionando e se legitimando ética e ideologicamente; ao mesmo tempo em que a formação docente se configura como lócus privilegiado para o acesso e a construção de outra práxis, na perspectiva histórica, política e social.

Com base nessa razão, o primeiro esforço do aparato jurídico-legislativo estatal, pós instituir a BNCC, foi viabilizar instrumentos legais de incidência direta nos projetos pedagógicos dos espaços institucionais de formação de professores em todo o território nacional. Para tanto, o CNE formalizou essa incidência pela aprovação da Resolução No 2, de 20 de dezembro de 2019 (BRASIL, 2019), propondo uma aproximação obediente dos projetos de formação de professores à lógica da BNCC. Essa Resolução, homologada pelo CNE, materializa a proposta da BNC-

Revista de Estudios Teóricos y Epistemológicos en Política Educativa, v. 6, e2118187, p. 1-17, 2021 Disponible en: <https://www.revistas2.uepg.br/index.php/retepe> 
Fundamentos político-pedagógicos da BNCC: considerações sobre o Estado educador e a produção...

Formação, que define as Diretrizes Curriculares Nacionais para a Formação Inicial de Professores para a Educação Básica e institui a Base Nacional Comum para a Formação Inicial de Professores da Educação Básica (BRASIL, 2019), expressa uma tentativa de formatar a formação de professor no Brasil, de modo a atender as competências e habilidades instituídas pela BNCC da Educação Básica.

A mediação do referencial teórico, aqui movimentado, permite constatar que a Resolução que institui a BNC-Formação guarda sintonia com as demandas hegemônicas do capital para a educação e para a política de formação de professores, objetivando a já indicada lógica homogeneizante e de controle, que não deixa margem para pensar a formação para a docência em uma perspectiva ampla e de promoção cultural. Para Farias (2019), essa Resolução sobreleva a noção de base nacional, mais alinhada às articulações discursivas da homogeneização, da eficácia e da avaliação, que, no limite, regula a própria práxis social possível no espectro dos projetos formativos dos profissionais da educação.

Contudo, convém destacar, ainda, que se trata de uma concepção restritiva amplamente criticada por pesquisadores do campo das políticas educacionais e por organizações representativas da área, como a Associação Nacional de Pós-Graduação e Pesquisa em Educação (ANPEd), que, por meio do texto "Uma Formação Formatada", expressa posicionamento contrário ao "Texto Referência - Diretrizes Curriculares Nacionais e Base Comum para a Formação Inicial e Continuada de Professores da Educação Básica", a partir da indicação de um conjunto de motivos, tais como: I) uma formação de professores de uma nota só; II) uma proposta de formação docente que ignora a indissociabilidade teoria prática; III) uma proposta de formação puxada pela competência socioemocional; IV) uma formação que não reconhece que o professor toma decisões curriculares (ANPED, 2019). Contudo, esses posicionamentos contrários e os esforços de resistência, no momento, não são suficientes, quer para abrir o diálogo com o Estado sob a mediação da racionalidade hegemônica neoliberal ou para proposições contra hegemônicas, no âmbito das políticas educacionais.

\section{Considerações finais}

Este trabalho, teórica e metodologicamente aportado na leitura gramsciana, parte do reconhecimento da natureza histórica e dialética da realidade, na qual se compreende o Estado como um todo complexo de atividades práticas e teóricas, enquanto hegemonia intelectual e moral de uma certa concepção de mundo. Em outras palavras, a afirmação histórica de um certo bloco como capacidade de domínio e direção, quer pela coerção, quer pelo consentimento voluntário do grupo dominado, tendo o Estado como organismo próprio deste grupo e a serviço de seu expansionismo. Assim, o Estado em ação, como na indução e na implementação de políticas, também das políticas educacionais, aqui representadas pela política curricular da BNCC, é assumido como estrutura mediada por uma concepção de sociabilidade hegemônica, portanto política e, consequentemente, pedagógica, que se expressa como e pelos aparelhos de hegemonia na produção e na validação de intencionalidades político-pedagógicas concernentes à sociabilidade vigente.

Por esse motivo, o esforço da análise aqui produzida está centrado na elucidação das relações de força que viabiliza a construção e a implementação da política curricular da BNCC, como relações características do Estado na qualidade de mediador de relações hegemônicas no contexto brasileiro. Resta indicado que: a reforma curricular da BNCC, enquanto ferramenta de intervenção política, portanto pedagógica do Estado, tanto incide sobre os processos de construção de consensos com marcada fidelidade à sociabilidade hegemônica, quanto busca disciplinar de forma direta a prática educativa. Incide, desse modo, sobre as próprias intencionalidades das comunidades educativas e, consequentemente, no controle e no disciplinamento das forças que

Revista de Estudios Teóricos y Epistemológicos en Política Educativa, v. 6, e2118187, p. 1-17, 2021 Disponible en: <https://www.revistas2.uepg.br/index.php/retepe>. 
possam indicar para a construção de outras experiências de sociabilidade que não aquela hegemônica.

Em outros termos, a política curricular como ferramenta do Estado neoliberal e seu compromisso político, por isso pedagógico, com a agenda de reestruturação da sociabilidade capital em curso no contexto brasileiro, expressa-se tanto como esforço de garantir a ampliação hegemônica desse modelo de Estado, viabilizando a inferência direta do mercado sobre a produção das políticas educacionais, quanto pela intervenção direta do Estado neoliberal sobre as intencionalidades político-pedagógicas da ação educativa; expressa tanto pelo apego às pedagogias das competências e o alinhamento das matrizes de oferta com as matrizes avaliativas, quanto pela indução de amplo processo de incidência sobre as políticas de formação dos profissionais da educação e a produção comercial dos sistemas de ensino.

Estas considerações, ao mesmo tempo que indicam para as principais conclusões da análise produzida, apontam para a necessidade de continuidade e aprofundamento das pesquisas, quer sobre a disciplinamento proposto para a política curricular da BNCC em si e no contexto do sistema educacional brasileiro, quer para o impacto da reforma curricular expressa na BNCC para o conjunto das políticas educacionais, com especial atenção para as políticas de formação de professores, avaliação, financiamento e produção de material didático.

\section{Referências}

ALVES, G. Trabalho e subjetividade: o espírito do toyotismo na era do capitalismo manipulatório. São Paulo: Boitempo, 2011.

ANPED. Associação Nacional de Pós-Graduação e Pesquisa em Educação. Uma formação formatada. Posição da ANPEd sobre o "Texto referência - Diretrizes Curriculares Nacionais e Base Nacional Comum para a Formação Inicial e Continuada de Professores da Educação Básica". 2019. Disponível em: https://www.anped.org.br/news/posicao-da-anped-sobre-texto-referenciaden-e-bncc-para-formacao-inicial-e-continuada-de. Acesso em: 10 ago. 2021.

ANTUNES, R. Os sentidos do trabalho: ensaios sobre a afirmação e a negação do trabalho. 2. ed. São Paulo: Boitempo, 2009.

ANTUNES, R. O privilégio da servidão: o novo proletariado na era digital. São Paulo: Boitempo, 2018.

ARAÚJO, D. S.; ALMEIDA, M. Z. C. M. de. Políticas Educacionais: refletindo sobre seus significados. Educativa, Goiânia, v. 13, n. 1, p. 97-112, jan./jun. 2010.

BENITE, A. M. C. Considerações sobre o enfoque epistemológico do Materialismo HistóricoDialético na Pesquisa Educacional. Revista Iberoamericana de Educación, [s. l.], n. 50, p. 1-15, set. 2019. DOI: https://doi.org/10.35362/rie5041887

BERNARDI, L. M.; UCZAK, L. H.; ROSSI, A. J. Relações do movimento empresarial na política empresarial brasileira: a discussão da base nacional comum. Currículo sem Fronteira, São Paulo, v. 18, n. 1, p. 29-51, jan./abr. 2018.

BRASIL. [Constituição (1988)]. Constituição da República Federativa do Brasil. Brasília, DF: Senado, 1988. 
Fundamentos político-pedagógicos da BNCC: considerações sobre o Estado educador e a produção...

BRASIL. Lei $\mathrm{N}^{\circ}$ 9.394, de 20 de dezembro de 1996. Estabelece as diretrizes e bases da educação nacional. Diário Oficial da União: seção 1, Brasília, DF, n. 248, p. 27833-27841, 23 dez. 1996.

BRASIL. Lei No 13.005, de 25 de junho de 2014. Aprova o Plano Nacional de Educação - PNE e dá outras providências. Diário Oficial da União: seção 1, Brasília, DF, n. 120-A, edição extra, p. 1-7, 26 jun. 2014.

BRASIL. Portaria No 592, de 17 de junho de 2015. Institui Comissão de Especialistas para a Elaboração de Proposta da Base Nacional Comum Curricular. Diário Oficial da União: seção 1, Brasília, DF, n. 114, p. 16, 18 jun. 2015.

BRASIL. Resolução $\mathbf{N}^{\mathbf{0}}$ 2, de 22 de dezembro de 2017. Institui e orienta a implantação da Base Nacional Comum Curricular, a ser respeitada obrigatoriamente ao longo das etapas e respectivas modalidades no âmbito da Educação Básica. Brasília: Ministério da Educação, Conselho Nacional de Educação, Conselho Pleno, [2017]. Disponível em: http://basenacionalcomum.mec.gov.br/images/historico/RESOLUCAOCNE_CP222DEDEZ EMBRODE2017.pdf. Acesso em: 10 ago. 2021.

BRASIL. Resolução $\mathbf{N}^{\circ}$ 2, de 20 de dezembro de 2019. Define as Diretrizes Curriculares Nacionais para a Formação Inicial de Professores para a Educação Básica e institui a Base Nacional Comum para a Formação Inicial de Professores da Educação Básica (BNC-Formação). Brasília:

Conselho Nacional de Educação; Conselho Pleno, [2019]. Disponível em: http://portal.mec.gov.br/docman/dezembro-2019-pdf/135951-rcp002-19/file. Acesso em: 10 ago. 2021.

ENGELS, F. A Origem da Família, da Propriedade Privada e do Estado. 9. ed. Rio de Janeiro: Civilização Brasileira, 1984.

FARIAS, I. M. S. O discurso curricular da proposta para BNC da formação de professores da educação básica. Revista Retratos da Escola, Brasília, v. 13, n. 25, p. 155-168, jan./maio 2019. DOI: https://doi.org/10.22420/rde.v13i25.961

FREITAS, L. C. de. Os reformadores empresariais da educação e a disputa pelo controle do processo pedagógico na escola. Educação \& Sociedade, Campinas, v. 35, n. 129, p. 1085-1114, out./dez. 2014. DOI: https://doi.org/10.1590/ES0101-73302014143817

FRIGOTTO, G. Enfoque da dialética materialista histórica na pesquisa educacional. In: FAZENDA, I. (org.). Metodologia da pesquisa educacional. São Paulo: Cortez, 1997. p. 69-90.

GIDDENS, A. A terceira via e seus críticos. Tradução Rita Vinagre. Rio de Janeiro: Record, 2001.

GRAMSCI, A. Maquiavel, a Política e o Estado Moderno. Rio de Janeiro: Civilização Brasileira, 1968 a.

GRAMSCI, A. Os intelectuais e a organização da cultura. Rio de Janeiro: Civilização Brasileira, $1968 \mathrm{~b}$.

JESUS, A. T. de. Educação e hegemonia no pensamento de Antonio Gramsci. São Paulo: Cortez, 1989.

MARTINS, A. S. Estratégias burguesas de obtenção do consenso nos anos de neoliberalismo da terceira via. In: NEVES, L. M. W. (org.). A nova Pedagogia da Hegemonia: estratégias do capital para educar o consenso. São Paulo: Xamã, 2005. p. 127-174.

Revista de Estudios Teóricos y Epistemológicos en Política Educativa, v. 6, e2118187, p. 1-17, 2021 Disponible en: <https://www.revistas2.uepg.br/index.php/retepe>. 
MARX, K.; ENGELS, F. Manifesto do Partido Comunista. São Paulo: Cortez, 1998.

MELO, A. A. S. de. Os Organismos Internacionais na construção de um novo bloco histórico. In: NEVES, L. M. W. (org.). A nova pedagogia da hegemonia: estratégias do capital para educar o consenso. São Paulo: Xamã, 2005. p. 69-82.

MELO, A. A. S. de; FALEIROS, I. Reforma da aparelhagem estatal: novas estratégias de legitimação social. In: NEVES, L. M. W. (org.). A nova pedagogia da hegemonia: estratégias do capital para educar o consenso. São Paulo: Xamã, 2005. p. 175-192.

MÉSZÁROS, I. A teoria da alienação em Marx. São Paulo: Boitempo, 2006.

NEVES, L. M. W.; SANT’ANNA, R. Introdução: Gramsci, o Estado educador e a nova pedagogia da hegemonia. In: NEVES, L. M. W. (org.). A nova pedagogia da hegemonia: estratégias do capital para educar o consenso. São Paulo: Xamã, 2005. p. 19-39.

RAMOS, M. N. A pedagogia das competências: Autonomia ou adaptação? 2. ed. São Paulo: Cortez, 2002.

SAVIANI, D. Marxismo, Educação e Pedagogia. In: SAVIANI, D.; DUARTE, N. (org.). Pedagogia histórico-crítica e luta de classes na educação escolar. Campinas: Autores Associados, 2015. p. 59-85.

SILVA, M. A. da. Intervenção e consentimento: a política educacional do Banco Mundial. Campinas: Autores Associados; São Paulo: FAPESP, 2002.

SILVA, M. R. da. A BNCC da Reforma do Ensino Médio: o resgate de um empoeirado discurso.

Educação em Revista, Belo Horizonte, v. 34, p.1-15, 2018. DOI: https://doi.org/10.1590/0102-4698214130

Recebido em 20/06/2021

Versão corrigida recebida em 12/08/2021

Aceito em 13/08/2021

Publicado online em 17/08/2021 